\title{
The Influence of Implicit Achievement Motive and Graphological Variables on Learning Variables
}

\author{
Nicole Gruber, Ludwig Kreuzpointner \\ Universität Regensburg, Regensburg, Germany \\ Email: Nicole.Gruber@ur.de, Ludwig.Kreuzpointner@ur.de
}

Received 7 July 2015; accepted 13 September 2015; published 17 September 2015

Copyright (C) 2015 by authors and Scientific Research Publishing Inc.

This work is licensed under the Creative Commons Attribution International License (CC BY). http://creativecommons.org/licenses/by/4.0/

(c) (i) Open Access

\begin{abstract}
There are several methods of implicit measurement. A very valid and wide spread assessment of motives by using the technique of projection is picture story exercises (PSE). Graphology, as theory of inferences on personality and motives by analyzing handwriting, is another one. The presented study examines the commons of the both measurement methods and their prediction of achievement behaviour. So, the achievement motive of 189 students was assessed using the PSE of Heckhausen (1963) and afterwards their handwriting was scored by a categorical system of Ploog (2013). Achievement related behaviour was operatively analyzed with self-reported learning time, learning behaviour and task-choice performance. It is shown that implicit motives measured by PSE are related with the criteria of task-choice performance. It is shown that both implicit motives measured by PSE and graphological variables deliver information about learning variables.
\end{abstract}

\section{Keywords}

Implicit Motive, Achievement, Thematic Apperception Test, Picture Story Exercises, Writing, Graphology, Measurement

\section{Introduction}

When searching for a method to measure motives, Murray (1938) used-influence by Freud (e.g. 1936)—-the construct of projection defined as a basic perception mechanism, which reflected inner unconscious wishes and feelings to the environment in case of need-satisfaction, for the development of the Thematic Apperception Test (TAT). This test is one of the most prominent tests universally called Picture Story Exercise (PSE). Therefore the subjects get presented pictures with the instruction to tell what they see, who the persons in the pictures are, 
what they feel, what was happened before, and how it will go on. Afterwards, these statements are analyzed with a content coding technique for implicit motives. According to McClelland (1985) it is assumed that especially the unconscious implicit achievement motive in contrast to the explicit achievement motive has an influence on how much energy is invested in a behaviour, e.g. how much time people spent on motive-relevant activities, like learning (Spangler, 1992). Frank (1948) stated unconscious wishes to be not only visible in perception, but also to modify automatic behaviour like the style of driving a car. So for example, a progressive driving style should be associated with an aggressive personality.

This assumption of projection was the cornerstone of graphology as a projective measure (Eberwein, 1993). Handwriting is commonly learned in school by templates indicating how high, how inclined a letter should be and how much distance should be between the words. When the years pass people individually change their writing-style as Müller and Enskat (1973) assume because of their personality. Tucha, Tucha and Lange (2008) found for a sample of persons with ADS that writing is an automated behaviour and cannot be controlled intentionally. Many different validation studies are run, some are summarized in meta-analysis e.g. by Dean (1992): the mean correlation of graphological scores with intelligence scores is 0.29 , with sex 0.32 , with personality traits between 0.08 and 0.16 . Mouly et al. (2007) predicted suicide attempts by having a look on the handwritings, so a specifity up to 0.82 was reached by graphological judgment. Some recent examples are Kraus (2011), who observed that people with high intelligence had a smaller handwriting than the normal population. Reviewing several studies Guthke et al. (2002) reported correlations of handwriting with intelligence in a range between -0.33 and 0.20. Emotional processes should be influence handwriting as well. So Luria and Rosenblum (2010) found that people wrote lies slightly shivering so that their fear could be read out of their handwritings. Also Tang (2012) assessed that lies could be seen in the handwriting.

However, conceptual assessment of handwritings is still lacking. Mostly graphologists perceive the whole handwriting and then get a result justified on several individual elements and the whole construction mostly on just a more or less comprehensible way (Lemke \& Kirchner, 1971). Beyerstein (2002), for example, mentioned that the principle psychometric criteria did not meet with graphology, by citing, for example, Goldberg (1986) and Dean (1992). Especially in the meta-analysis with more than 200 studies, Dean (1992) found low correlations of graphological protocols and e.g. personality dispositions. Also Neter and Ben-Shakhar (1989) reported by analyzing 17 studies that graphological analysis from experts were not more validly than random. Beyerstein (2002) by referencing on Dean (1992) claimed that this was because the graphological effect was too small, the graphological methods were too many and there were more variables in the dark that influenced this interplay. Wallner (2002) analyzed different aspects of graphology and found that they could simply not be seen independently, for example, maturity and regularity of writing correlate with 0.54 . Despite this fact that graphological analysis is used in over $80 \%$ of employments companies in Europe (Greasley, 2000). In some cases the graphological experts also disagree in their ratings (Beyerstein, 2002). Also Dazzi and Pedrabissi (2009) found that graphology did not correlate with personality variables, despite they also had low inter-rater-agreement. On the other hand, King and Koehler (2000) reported in a study with ten graphologists that the inter-rater-agreement was in an acceptable range from 0.89 to 0.97 , but just for individual writing features instead of the whole impress.

Ploog $(2008,2013)$ wrote a manual for easy graphological coding, referring what each individual feature means. It is based on a practical using guide of Müller and Enskat (1973) and the data of the psychopathic clients that are described there. For example, depressive people should write smaller and their writings tend little to left.

Because both, the PSE and graphological analysis pretend to measure on the implicit system it is questioned in this study, whether they correlate with each other and how well they predict behaviour that is commonly induced by implicit correlates. Therefore the implicit achievement motive is chosen. The assessment of this motive with PSE is widely researched over decades. Heckhausen (1963) split the PSE measurement of the implicit achievement motive into the two components hope of success (HS) and fear of failure (FF). In current research (e.g. the quadripolar model of Covington and Roberts, 1994) it is shown that people high in HS tend to better grades, invest more learning time, choose more realistic goals and show more productive learning behaviour. On the other hand students high in FF mostly choose too hard or too simple goals, they start too late with learning and sometimes show self-handicapping tendencies, so that they do not attribute the failure to themselves but to their self-protecting behaviour. Those high in HS and FF are called over striver, they mostly setting themselves high goals, spend much time in learning and have the best grades, but often get in the risk of burnout. People with low HS and FF are called failure accepter; they do not show learning behavior (Atkinson, 1966; Heckhau- 
sen, 1963; Chen et al., 2009; De Castella et al., 2013).

Ploog $(2008,2013)$ assumed that motivation and vitality can be seen in handwriting, especially those motivation stable over time. According to his graphological content coding system of people with high HS-scores have a great writing-size (> $3.3 \mathrm{~mm}$ ) and great distance between words. Their direction of line rises, letters tilt to right, they write faster, what is associated with ongoing i-dotting, and the writing has more pressure, which can be seen in the broadness of letters. Otherwise for people with high FF-scores, the words should be small $(<2.5 \mathrm{~mm})$ with little distance between them. Their direction of line is descendent, letters tilt to left, the speed of their writing is low with less pressure, just small tiny lines are expected. It is assumed that these six graphological categories correlate with implicit motives and therefore are also related with learning time, learning behaviour and task-choice performance. For people high in HS spend more time in learning and show positive learning behaviour as well as they set themselves realistic goals. On the other hand, people with high FF should show negative learning behaviour and set themselves unrealistic goals. So great writing-size, great distance between the words, rising line-direction, and right slanted letters with high writing-speed and -pressure should belong to a person with high HS (Ploog, 2013). On the other side people with low writing-size, low word distance, descendentline-direction, left tilted letters, low speed and pressure should show high FF (Ploog, 2013). Oosthuizen (1990) analyzed the correlation of questionnaire and graphological indices with learning and achievement and found that graphology better predicts those scores than questionnaires. Also Lowis and Mooney (2001) assessed the conjunction of graphology with the achievement of students and found that the individual feature slant can predict achievement.

So the research questions for this study are:

1) If handwriting-scores and implicit achievement motive-scores correlate, in the fact that both should refer to the unconscious system;

2) If handwriting-scores and implicit achievement motives can predict achievement behaviour that is related to unconscious processes (e.g. task-choice, learning time and learning behaviour).

\section{Method}

\subsection{Participants, Material and Procedure}

On this study 189 students (136 women, $53 \mathrm{men})$ at the age of 18 to 34 years old $(M=22.16, S D=2.96)$ participated. They were on average in the fourth semester $(S D=1.79)$ enrolled in different disciplines at the university.

The main material was the picture story exercise of Heckhausen (1963) assessing the two components of achievement motive hope of success (HS) and fear of failure (FF). Heckhausen (1963) used six pictures: a smiling man at the desk (picture A), a man in front of the directors room (B), two men on a workbench (C), a pupil on the blackboard (D), a man working at the desk (E), two men on a machine (F). Three of them mainly activate HS (A, C, E) and three activate FF (B, D, F). The coding system of Heckhausen (1963; English language translation by Schultheiss, 2001) differs HS and FF each by seven categories: the instrumental activities to achieve success resp. to avoid failure (IS/IF), the affective state $\left(\mathrm{A}+/ \mathrm{A}^{-}\right)$, the expected goal state (ES/EF), praise and criticism (P/C), the need for achievement (NS/NF), failure (F) and the achievement theme (ST/F). Additionally the new category "success" (Esg) introduced by Breidebach (2012) was used, which represented the opposite of failure. For each picture the categories were summed up for each HS and FF. The handwriting of the subjects was analyzed using the categorical system of Ploog (2008, 2013) regarding the six individual features writing-size, slant, line-direction, word distance, writing-speed and writing pressure on the script of the PSE sheets.

For measuring learning behaviour and task-choice two tests detailed described in Gruber (2014) were used. In the task-choice test nine drawing exercises were presented, three easy, three medium and three hard. In the first part of the test the participants have to reckon how well they think they can solve this kind of drawing exercises. Then they have to choose three drawings, they want to solve. It is assumed that people with high HS choose solvable tasks; for example when someone has low experience in solving the task then he will choose three easy one. For each so "correct" choice a score of 1 is given. Next, a questionnaire for learning behaviour was given to the participants; it includes five items of positive learning behavior (Cronbach's $\alpha=0.69$ ) like going through the script again and again as well as seven items of negative learning behavior (Cronbach's $\alpha=0.70$ ) as e.g. forgetting to learn before examination and then later drink alcohol (for details see Gruber, 2014).

People first absolved the PSE: Each of the six pictures was presented for 20 seconds. Then the subjects had five minutes to answer the following four questions: 1) What is going on? Who are the people? 2) What has led 
to this situation? What has happened before? 3) What are the people thinking about, feeling, or wanting? 4) What will happen next? How will everything turn out? All pictures were presented strictly following the instructions of Heckhausen (1963). For example, the timing was done casually and the instruction was given literally. The students wrote with pencil on unlined A4-paper-sheets, so they have all possibilities to express their personality in their writings. After the PSE subjects got a questionnaire for demographical data (sex, age, study subject and semester), the questionnaire for learning behaviour and the task-choice performance test.

\subsection{Analysis}

The inter-rater-agreement between both PSE coders was assessed using the $\mathrm{a}_{\mathrm{d}}$-coefficient (Kreuzpointner et al., 2010) and bravais-pearson correlations (given in brackets). The $\mathrm{a}_{\mathrm{d}}$-coefficient was 0.996 for HS $(r=0.93)$ and 0.998 for FM $(r=0.89)$, which indicates statistical and practical significant agreement of both raters on the 95\% level. The handwritings were also scored by two independent coders using the manual of Ploog (2008). Therefore also the inter-rater-agreement of two independent coders was calculated with bravais-pearson correlations and the $\mathrm{a}_{\mathrm{d}}$-coefficient. The $\mathrm{a}_{\mathrm{d}}$-coefficients were for word size $0.946(r=0.84)$, for word distance $0.925(r=0.83)$, for slant $0.949(r=0.86)$, for line-direction $0.991(r=0.90)$, for speed $0.990(r=0.91)$ and for pressure $0.950(r$ $=0.87$ ), which only for line-direction and speed was above the $95 \%$ significance-level.

To assess the relations of graphological measurements and implicit motives a regression was calculated with hope of success (HS), fear of failure (FF) and their interaction HSxFF as factors. This was leant on the assumptions of Ploog $(2008,2013)$ that each individual graphological feature is related to HS or FF and their interaction. For the relationship of graphological measurement, implicit motives correlations and partial correlations were calculated. Furthermore, the influence of HS and FF is partialled out of the graphological scores so that it is visible how much variance is explained just by the graphological measurements. For an interrelation of the implicit motives and graphological scores, correlations were calculated. Last, the relation of graphological scores and motive-scores with learning time, positive and negative learning behaviour and correct task-choices was calculated via multiple regressions.

\section{Results}

As seen in Table 1 there is only a small correlation of pressure and speed $(r=-0.17, p<0.05)$ and a medium correlation of speed and slant $(r=0.41, p<0.01)$. All other factors excepting speed are unrelated to each other with correlations between -0.13 and 0.10 . The achievement components HS and FF correlate moderate with 0.35 .

Also shown in Table 1 the implicit motives hope of success (HS) and fear of failure (FF) correlate low with the six graphological individual features. Only size shows a statistically significant correlation with HS $(r=-0.17)$ in the way the smaller people write the higher is their implicit hope of success motive. There are also just low correlations with the interaction term, which is more affected by FF (75\%) than by HS (25\%).

In Table 2 the results of six univariate linear regressions with the implicit motive variables as predictive factors on the components of the writing style are shown. The multiple correlations are low (between 0.08 and $0.21)$, and so the explained variance. High HS and FF predict low speed $(-0.32$ and -0.38$)$ but for both variables high the interaction term has a compensating effect $(0.29)$. High HS and FF predict low writing-size $(-0.30$, and -0.26 ) alike with a compensating interaction (0.16). The third effect of this kind is for low slant (with standardized regression weights -0.25 for HS, -0.36 for FF and 0.26 for HSxFF).

Table 3 gives an overview of the correlations between implicit motives HS and FF as well as achievement behaviour and the six graphological factors. HS shows statistically significant correlation with correct choice $(r=-0.17)$ and learning time $(r=-0.22)$ in the opposite direction than expected. FF correlates with learning time $(r=0.18)$. The interaction term HSxFF has no relevant effect for the achievement behaviour. The assessment of writing-speed and word distance shows statistically significant correlations with task-choice performance ( $r=0.17$ and 0.18 ), but not with learning time and positive or negative learning.

When partialing out the influence of HS and FF, speed becomes one central predictor for achievement behaviour especially for task-choice performance $(r=0.16)$. Pressure, size, and line-direction have no statistically significant correlations with the achievement behaviours. Only word distance $(r=0.18)$ and speed $(r=0.17)$ are associated with correct choice, after controlling the influences of HS and FF this effect remains. When the motive-scores are controlled slant gets a statistically significant influence on learning time $(r=0.14)$. So people with right slanted letters spend more time on learning. 
The regression analysis shown in Table 4 demonstrates that the graphological scores as well as the implicit Table 1. Intercorrelations of the six individual graphological features with hope of success (HS) and fear of failure (FF).

\begin{tabular}{ccccccccc}
\hline & Speed & Pressure & Size & Slant & Distance & Line-direction & HS & HSxFF \\
\hline Speed & & $-0.17^{*}$ & -0.12 & $0.41^{* *}$ & -0.04 & -0.09 & -0.12 & 0.07 \\
Pressure & $-0.17^{*}$ & & 0.09 & -0.09 & -0.13 & 0.08 & 0.05 & 0.04 \\
Size & -0.12 & 0.09 & & 0.02 & 0.09 & -0.03 & $-0.17^{*}$ & -0.11 \\
Slant & $0.41^{* *}$ & -0.09 & 0.02 & & -0.06 & -0.06 & -0.06 & 0.07 \\
Distance & -0.04 & -0.13 & 0.09 & -0.06 & & -0.07 & -0.13 & 0.09 \\
Line-direction & -0.09 & 0.08 & -0.03 & -0.06 & -0.07 & & 0.02 & 0.06 \\
FF & 0.05 & -0.07 & 0.04 & -0.08 & -0.01 & 0.10 & $0.35^{* *}$ & $0.75^{* *}$ \\
\hline
\end{tabular}

Note: HS $=$ hope of success, FF $=$ fear of failure, ${ }^{*} p<0.05,{ }^{* *} p<0.01$.

Table 2. Standardized regression weights of the two implicit motives hope of success (HS) and fear of failure (FF) and their interaction for the six linear regression on each graphological feature (depend variables).

\begin{tabular}{cccccc}
\hline & HS & FF & HSxFF & R & $\mathrm{R}^{2}$ \\
\hline Speed & $-0.32^{*}$ & $-0.38^{*}$ & 0.29 & 0.18 & 0.03 \\
Pressure & 0.01 & -0.10 & 0.03 & 0.08 & 0.01 \\
Size & $-0.30^{*}$ & -0.26 & 0.16 & 0.21 & 0.04 \\
Slant & -0.25 & $-0.36^{*}$ & 0.26 & 0.16 & 0.02 \\
Distance & -0.05 & 0.11 & -0.16 & 0.15 & 0.02 \\
Line-direction & 0.14 & 0.29 & -0.19 & 0.13 & 0.02 \\
\hline
\end{tabular}

Note: HS $=$ hope of success, FF $=$ fear of failure, ${ }^{*} p<0.05,{ }^{* *} p<0.01$.

Table 3. Bivariate correlations and correlations controlled for the implicit motives hope of success (HS) and fear of failure (FF) as well as the six individual feature of graphology with the four factors of achievement behaviour.

\begin{tabular}{|c|c|c|c|c|}
\hline & Learning time & Positive learning behaviour & Negative learning behaviour & Correct choices \\
\hline HS & $-0.22^{* *}$ & -0.10 & -0.10 & $-0.17^{*}$ \\
\hline $\mathrm{FF}$ & $0.18^{*}$ & 0.06 & 0.06 & 0.09 \\
\hline HSxFF & -0.02 & 0.01 & -0.02 & -0.03 \\
\hline Speed & 0.09 & 0.01 & -0.13 & $0.17^{*}$ \\
\hline Pressure & -0.03 & 0.06 & 0.02 & -0.09 \\
\hline Size & 0.02 & 0.01 & 0.04 & 0.01 \\
\hline Slant & 0.12 & -0.03 & -0.06 & 0.04 \\
\hline Distance & -0.01 & 0.04 & 0.03 & $0.18^{*}$ \\
\hline \multirow[t]{3}{*}{ Line-direction } & 0.01 & 0.04 & -0.03 & 0.01 \\
\hline & \multicolumn{4}{|c|}{ correlation with constant motive-scores HS and FF } \\
\hline & Learning time & Positive learning behaviour & Negative learning behaviour & Correct choices \\
\hline Speed & 0.08 & 0.05 & 0.13 & $0.16^{*}$ \\
\hline Pressure & -0.02 & 0.06 & 0.03 & -0.08 \\
\hline Size & 0.00 & 0.04 & 0.06 & -0.02 \\
\hline Slant & 0.14 & 0.04 & 0.08 & 0.04 \\
\hline Distance & -0.05 & -0.02 & -0.06 & $0.17^{*}$ \\
\hline Line-direction & 0.00 & 0.04 & -0.01 & -0.01 \\
\hline
\end{tabular}

Note: $\mathrm{HS}=$ hope of success, $\mathrm{FF}=$ fear of failure, ${ }^{*} p<0.05,{ }^{* *} p<0.01$. 
Table 4. Standardized regression weights of the handwriting and implicit motives indices on achievement criteria learning time, positive and negative learning behaviour and task-choice performance.

\begin{tabular}{ccccc}
\hline & Learning time & Positive learning behaviour & Negative learning behaviour. & Correct choices \\
\hline Speed & 0.05 & 0.02 & -0.14 & $0.17^{*}$ \\
Pressure & 0.00 & 0.07 & 0.00 & -0.03 \\
Size & 0.01 & -0.01 & 0.01 & 0.00 \\
Slant & 0.11 & -0.03 & -0.00 & -0.02 \\
Distance & -0.04 & 0.04 & 0.01 & $0.17^{*}$ \\
Line-direction & -0.01 & -0.03 & -0.05 & 0.01 \\
HS & 0.11 & -0.16 & -0.05 & -0.06 \\
FF & $0.59^{* *}$ & -0.09 & 0.12 & 0.12 \\
HSxFF & $-0.49^{*}$ & 0.12 & -0.10 & -0.08 \\
R & 0.33 & 0.14 & 0.18 & 0.29 \\
R & 0.11 & 0.02 & 0.03 & 0.09 \\
\hline
\end{tabular}

Note: HS = hope of success, FF = fear of failure, ${ }^{*} p<0.05, \stackrel{* *}{p}<0.01$.

motive-scores cannot predict learning behaviour very well. Just writing-speed provides some predictive power for negative learning behaviour $(-0.14)$ and the amount of correct choices $(0.17)$. The high loadings of FF (0.59) and HSxFF (-0.49) on learning time are consequences of their high inter-correlation (0.75) and the opposite bivariate correlation of HS and FF with learning time. The regression coefficients are low (0.14 to 0.33$)$, so the explanation of variance of the learning criteria becomes maximal $11 \%$.

\section{Discussion}

This study first examined the question of the relationship between handwriting and implicit motives. The result was that implicit achievement motive couldn't totally be found in handwriting. Only writing-size and speed showed little interrelation with the HS-score as well as speed and slant with the FF-score. This could be interpreted like Heckhausen (1963) did that the myotonic of people high in HS was higher than that of FF-related persons. So the higher the tense of the muscles of a person, the more indistinct is found in their writings. Perhaps this result could also explain the assumptions of Kraus (2011) that size could play a role in achievement related behaviour with intelligence testing. This does not mean that graphological measurements are commonly related with implicit motives, especially pressure, distance and line-direction, so the central individual feature of writing analysis is not related to any of the implicit achievement motives. Furthermore, it could not be attested that the six graphological features are unrelated with each other, for speed and slant show a moderate inter-correlation.

Secondly, it was researched how handwriting and implicit motive-scores influenced achievement behaviour. According to our assumptions, implicit motive-scores are related to learning time and task-choice performance. Learning time is only in the regression influenced by an interaction of HS and FF as assumed in the quadripolar model of Covington and Roberts (1994). Correct choices are only related to the HS-score. This linear influence of implicit motives, which Heckhausen (1963) also found when testing his PSE, is against some newer results of de Castella et al. (2013). In another study, Gruber (2014) also reported that the data of the paper-pencil-version did not perfectly fit the quadripolar model, but when using the PSE as a computer-test a good representation of the model in the data could be attested.

Surprisingly, the graphological factors can predict achievement behaviour independently from implicit motives. So, handwriting could deliver new information beyond the implicit motive measured by PSE, especially more practical scores like learning time and task choice performance. This leads to a new point of view: both PSE and graphology can measure different aspects of unconsciousness on an implicit level. For example, Stiller and Breidebach (in prep.) find that pupil can be primed and afterwards assessed with the PSE are more achievement related than others not primed. In addition, nonverbal information like mimic and facial expressions can also influence achievement motives at this point of state (Schultheiss, 2008). But the graphological unconscious seems to be another one, which perhaps may rather base on the motoric system than on the implicit associative network and so it may assess some unspecific core of personality (Guthke et al., 2002). Therefore 
more researches are needed. Regarding neuronal correlations of implicit motives there are some results (Hall, Stanton \& Schultheiss, 2010), but much more is required for graphology.

A limitation of this study is that the test was timed and so the correlation between speed and learning time as well as learning behaviour can be lead back to an achievement character of the situation. For example, Winter (1993) reports that people who write more (and write faster) also have a higher achievement motive. It is recently shown by Gruber and Kreuzpointner (in prep.) as well as by Gruber (2014) that the achievement motive measured with the coding system of Heckhausen is not related to word-count. Also the correlation of slant and speed could cause the correlation of slant and achievement behaviour.

In summary, this investigation gives a few hints that there are more layers of unconsciousness that can further be assessed. For example, the connection of drawing tests and graphology could be researched in further investigations, for both are expressive projective techniques. Such drawing test could be the Wartegg-drawing test (Wartegg, 1954) or the draw-a-tree-test (Ave-Lallemant, 2010). Some possible research-questions can be if the appearance of the trees is related with handwriting, so that big trees in the "draw-a-tree-test”are associated with big letters ora tree hanging to the left side is associated with left slanted handwritings.

\section{Acknowledgements}

We specially want to thank Dr. Helmut Ploog for recoding the graphological score and Christina Hanauer for recoding the TAT/PSE-scores. We are also grateful to the anonymous reviewers of previous versions of the manuscript for their constructive critics. This work was supported by the German Research Foundation (DFG) within the funding program Open Access Publishing.

\section{References}

Atkinson, J. W. (1966). Motives in Fantasy, Action, and Society. Princeton, NJ: Van Nostrand.

Ave-Lallemant, E. (2010). Baum-Test. Mit einer Einführung in die symbolische und graphologische Interpretation (TreeTests. With an Introduction in the Symbolic and Graphological Interpretation). Stuttgart: Reinhard.

Beyerstein, B. L. (2002). How Graphology Fools People. Quackwatch. http://www.quackwatch.org/01QuackeryRelatedTopics/Tests/grapho.html

Breidebach, G. (2012). Bildungsbenachteiligung-Warum die einen nicht können und die anderen nicht wollen (Educational Disadvantage-Why Some Can'T and Others Don't Want). Hamburg: Kovacs.

Chen, L. H., Wu, C.-H., Kee, Y. H., Lin, M.-S., \& Shui, S.-H. (2009). Fear of Failure, $2 \times 2$ Achievement Goal and SelfHandicapping: An Examination of the Hierarchical Model of Achievement Motivation in Physical Education. Contemporary Educational Psychology, 34, 298-305. http://dx.doi.org/10.1016/j.cedpsych.2009.06.006

Covington, M. V. \& Roberts, B. W. (1994). Self-Worth and College Achievement: Motivational and Personality Correlates. In P. R. Pintrich, D. R. Brown, \& C. E. Weinstein (Eds.), Student Motivation, Cognition and Learning (pp.157-188). Hillsdale, NJ: Erlbaum.

Dazzi, C., \& Pedrabissi, L. (2009). Graphology and Personality: An Empirical Study on Validity of Handwriting Analysis. Psychological Reports, 105, 1255-1268. http://dx.doi.org/10.2466/PR0.105.F.1255-1268

De Castella, K., Byrne, D., \& Covington, M. (2013). Unmotivated or Motivated to Fail? A Cross-Cultural Study of Achievement Motivation, Fear of Failure, and Student Disengagement. Journal of Educational Psychology, 105, 861-880. http://dx.doi.org/10.1037/a0032464

Dean, G. A. (1992). The Bottom Line: Effect Size. In B. L. Beyerstein, \& D. F. Beyerstein (Eds.), The Write Stuff: Evaluation of Graphology —The Study of Handwriting Analysis (pp. 269-341). Buffalo, NY: Prometheus.

Eberwein, M. (1993). Projektive Verfahren (Projective Measurements). Trier: ZPID.

Frank, L. K. (1948). Projective Methods. Springfield: Charles C. Thomas.

Freud, A. (1936). Das Ich und die Abwehrmechanismen (The Ego and Mechanisms of Defense). Frankfurt: Fischer.

Greasley, P. (2000). Handwriting Analysis and Personality Assessment. European Psychologist, 5, 44-51. http://dx.doi.org/10.1027//1016-9040.5.1.44

Gruber, N. (2014). Ist eine Computerversion bei der Messung impliziter Motive der Papier-Bleistift-Version überlegen: Eine Untersuchung am Beispiel des TAT nach Heckhausen (Is a Computer-Version Superior to the Paper-Pencil-Version in Measuring Implicit Motives? An Investigation Using the TAT/PSE of Heckhausen). Regensburg: Roderer. http://www-lukesch.uni-regensburg.de/TAT/thesis.html

Gruber, N., \& Kreuzpointner, L. (in prep.). Assessing the Implicit Achievement Motives: Effects of Input-Condition, Administration and Picture-Position. 
Guthke, J., Beckmann, J. F., \& Schmid, G. (2002). Ist an der Graphologie doch etwas dran? Untersuchungen zur Übereinstimmung von Graphologenurteil und psychometrischen Persönlichkeitstests (Is Graphology of Value after All? On the Relationship between Graphological Judgment and Psychometric Personality Tests). Zeitschrift für Personalpsychologie, 1, 171-176. http://dx.doi.org/10.1026//1617-6391.1.4.171

Hall, J. L., Stanton, S. J., \& Schultheiss, O. C. (2010). Biopsychological and Neural Processes of Implicit Motivation. In O. C. Schultheiss, \& J. C. Brunstein (Eds.), Implicit Motives (pp. 279-307). New York: Oxford University Press.

Heckhausen, H. (1963). Hoffnung und Furcht in der Leistungsmotivation (Hope and Fear Components of Achievement Motivation). Meisenheim am Glan: Anton Hain.

King, R. N., \& Koehler, D. J. (2000). Illusory Correlations in Graphological Inference. Journal of Experimental Psychology: Applied, 6, 336-348. http://dx.doi.org/10.1037/1076-898X.6.4.336

Kraus, E. (2011). Hochintelligenz und Handschriftendiagnostik-Analyse der relevanten Schriftmerkmale (High-Intelligence and Writing Diagnostics_-Analysis of Relevant Writing Factors). Grafologie News, 9, 1-17.

Kreuzpointner, L., Simon, P., \& Theis, F. J. (2010). The Ad Coefficient as a Descriptive Measure of the Within-Group Agreement of Ratings. British Journal of Mathematical and Statistical Psychology, 63, 341-360. http://dx.doi.org/10.1348/000711009X465647

Lemke, E. A., \& Kirchner, J. H. (1971). A Multivariate Study of Handwriting, Intelligence, and Personality Correlates. Journal of Personality Assessment, 35, 584-592. http://dx.doi.org/10.1080/00223891.1971.10119716

Lowis, M. J., \& Mooney, S. (2001). Examination Performance and Graphological Analysis of Students’ Handwriting. Perceptual and Motor Skills, 93, 367-381. http://dx.doi.org/10.2466/pms.2001.93.2.367

Luria, G., \& Rosenblum, S. (2010). Comparing the Handwriting Behaviours of True and False Writing with Computerized Handwriting Measures. Applied Cognitive Psychology, 24, 1115-1128. http://dx.doi.org/10.1002/acp.1621

McClelland, D. C. (1985). Human Motivation. Glenview: Scott, Foresman and Co.

Mouly, S., Mahé, I., Champion, K., Bertin, C., Popper, P., De Noblet, D., \& Bergmann, J. F. (2007). Graphology for the Diagnosis of Suicide Attempts: A Blind Proof of Principle Controlled Study. International Journal of Clinical Practice, 61, 411-415. http://dx.doi.org/10.1111/j.1742-1241.2006.00960.x

Müller, W. H., \& Enskat, A. (1973). Graphologische Diagnostik Ihre Grundlagen, Möglichkeiten und Grenzen (Graphological Diagnostics, Theirbasics, Changes and Limits). Bern: Huber.

Murray, H. A. (1938). Explorations in Personality. New York: Oxford University Press.

Neter, E., \& Ben-Shakhar, G. (1989). The Predictive Validity of Graphological Inferences: A Meta-Analytic Approach. Personality and Individual Differences, 10, 737-745. http://dx.doi.org/10.1016/0191-8869(89)90120-7

Oosthuizen, S. (1990). Graphology as Predictor of Academic Achievement. Perceptual and Motor Skills, 71, 715-721.

Ploog, H. (2008). Handschriften deuten (Handwriting Analysis). Hamburg: Humboldt.

Ploog, H. (2013). Handwriting Psychology: Personality Reflected in Handwriting. London: Universe.

Schultheiss, O. C. (2001). Manual for the Assessment of Hope of Success and Fear of Failure: English Translation of Heckhausen's Need Achievement Measures. Unpublished Scoring Manual, Ann Arbor, MI: University of Michigan.

Schultheiss, O. C. (2008). Implicit Motives. In O. P. John, R. W. Robins, \& L. A. Pervin (Eds.), Handbook of Personality: Theory and Research (3rd ed., pp. 603-633). New York: Guilford Press.

Spangler, W. D. (1992). Validity of Questionnaire and TAT-Measures of Need for Achievement: Two Meta-Analyses. Psychological Bulletin, 112, 140-154. http://dx.doi.org/1.1037/0033-2909.112.1.140

Stiller, K. D., \& Breidebach, G. (in prep.). Priming and Achievement Motivation at School.

Tang, T. L. (2012). Detecting Honest Peoples Lies in Handwriting. Journal of Business Ethics, 106, 389-400. http://dx.doi.org/10.2307/41426702

Tucha, O., Tucha, L., \& Lange, K. W. (2008). Graphonomics, Automaticity and Handwriting. Literacy, 42, 145-155. http://dx.doi.org/10.1111/j.1741-4369.2008.00494.x

Wallner, T. (2002). Die Handschriftendiagnostik in der Meta-Analyse (Diagnostics of Handwriting in a Meta-Analytisis). Zeitschrift für Menschenkunde, 58, 158-163.

Wartegg, E. (1954). Der Zeichentest (WZT). Einführung in die graphoskopische Schichtdiagnostik. In E. Stern (Ed.), Handbuch der klinischen Psychologie. Band 1. Die Tests in der klinischen Psychologie. 2. Halbband (Handbook of Clinical Psychology. Volume 1. Tests in Clinical Psychology. 2nd Half Volume) (pp. 520-587). Stuttgart \& Zürich: Rascher Verlag.

Winter, D. G. (1993). Power, Affiliation, and War. Journal of Personality and Social Psychology, 65, 532-545. http://dx.doi.org/10.1037/0022-3514.65.3.532 